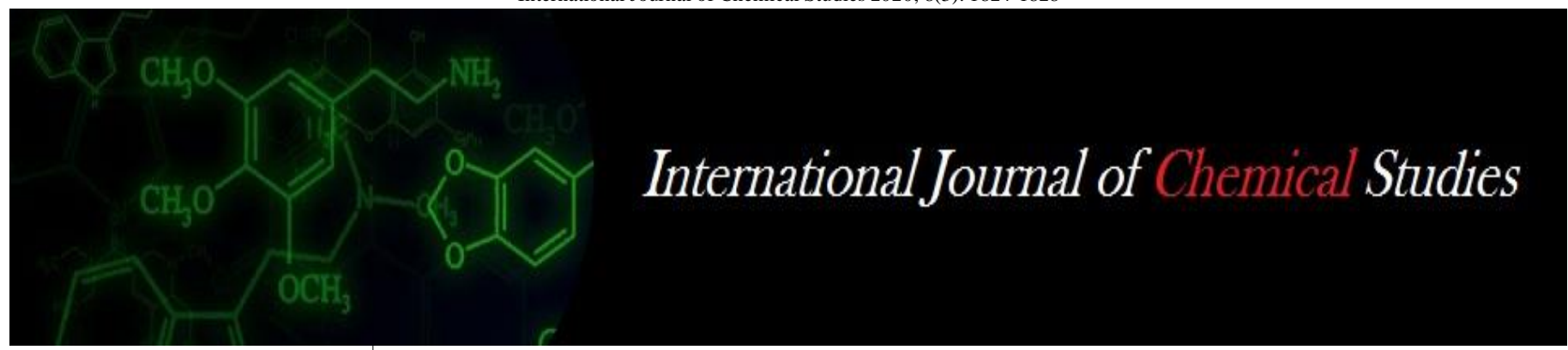

P-ISSN: 2349-8528

E-ISSN: 2321-4902

www.chemijournal.com

IJCS 2020; 8(3): 1824-1828

(C) 2020 IJCS

Received: 18-03-2020

Accepted: 20-04-2020

Singh Shruti V

Department of Environmental

Science and Natural Resource

Management, College of

Forestry, Sam Higginbottom

University of Agriculture,

Technology and Sciences,

Prayagraj, Uttar Pradesh, India

Sanadya Anurag

Department of Environmental

Science and Natural Resource

Management, College of

Forestry, Sam Higginbottom

University of Agriculture,

Technology and Sciences,

Prayagraj, Uttar Pradesh, India

Yadu Avinash

Department of Agrometeorology,

Indira Gandhi Krishi

Vishwavidyalaya, Raipur,

Chhattisgarh, India
Corresponding Author: Singh Shruti V

Department of Environmental

Science and Natural Resource

Management, College of

Forestry, Sam Higginbottom

University of Agriculture,

Technology and Sciences,

Prayagraj, Uttar Pradesh, India

\section{Simulating the impact of climate change on rice yield using DSSAT model}

\author{
Singh Shruti V, Sanadya Anurag and Yadu Avinash
}

DOI: https://doi.org/10.22271/chemi.2020.v8.i3y.9473

\begin{abstract}
Rice (Oryza sativa L.) is the second most important food grain after wheat in World. A decline in productivity of rice in recent years has been ascribed to decrease in soil organic carbon and reserve of nutrients, non-uniform distribution of rainfall, and increase in temperature and carbon dioxide because of climate change. To assess the impact of climate change on rice yield, crop simulation DSSAT model CERES - rice was calibrated and well evaluated for short and medium duration varieties through field experimental data at Prayagraj, India. Using past 8 years $(2012$ - 2019) weather data, the CERES-Rice model predicted higher yield variability of the medium duration variety (130 days) "NDR - 359" as compared to the short duration (90 days) variety "NDR - 97" under irrigated condition of Prayagraj, India. However NDR - 359 simulated the higher mean yield. With increase in atmospheric $\mathrm{CO}_{2}$ level by $150 \mathrm{ppm}$, the grain yield of NDR - 359 and NDR - 97 was increased by $7.16 \%$ and $5.86 \%$ respectively under irrigated condition. Increase in average air temperature by $3^{\circ} \mathrm{C}$ resulted a decline in yield of short duration variety but an increase in yield of the medium duration variety. The medium duration variety showed better adaptability to climate change than the short duration varieties under optimum input management condition.
\end{abstract}

Keywords: DSSAT CERES-rice model, climate change, rice yield, simulation

\section{Introduction}

Rice (Oryza sativa L.) is a grain plant belonging to the family Poaceae and genus Oryza with chromosome no. $=24$. Rice is one of the most important food grains produced and consumed all over the world. It is a subsistence crop for most farmers. Rice is the longest continuously grown cereal crop in the world and according to the International Rice Research Institute (IRRI) it is "one of the most important developments in history". Rice (Oryza sativa L.) is one of the most important staple food crop of India for more than $2 / 3 \mathrm{rd}$ of its population. The slogan "Rice is life" can be considered appropriate for our country as this crop plays a vital role in our national food security and is a means of livelihood for millions of rural households. Rice is one of the world's largest cereal crop providing the caloric need for millions of people. India produces 99.15 million tons of rice (Anonymous, 2009) while China is first in rice production in the world (Anonymous, 2007). However, at the current rate of population growth, rice production has to enhance to about 120 million tons by 2020 (Survey of Indian Agriculture, 2005).

Since the beginning of the 1980s a threat to agriculture has attracted much attention is climate change due to global warming. Many climatologists predict significant global warming in the coming decades due to increasing concentration of $\mathrm{CO} 2$ and other greenhouse gases in the atmosphere. The $\mathrm{CO} 2$ concentration has been projected to increase to 670 to $760 \mu \mathrm{mol}$ mol-1 by the year 2075 due mainly to continued burning of fossil fuel (Rotty and Marland, 1986). The increasing concentration of $\mathrm{CO}_{2}$ may have significant effect on rice productivity due to increase in both the average surface temperature and the amount of $\mathrm{CO}_{2}$ available for photosynthesis (Aggarwal, 2003) ${ }^{[1]}$. In the absence of temperature increase, many studies have shown that the net effect of doubling of $\mathrm{CO} 2$ was increase in the yield of rice (Kim et al., 2003; Baker et al., 1992; Baker et al, 2000) ${ }^{[2,9,3]}$. Baker et al. (1992) ${ }^{[2]}$ stated that potentially large negative effects on rice yield are possible with increase in atmospheric $\mathrm{CO} 2$, if air temperatures also rise.

It is felt that global warming will affect agricultural production directly because of alterations 
in temperature and rainfall, and indirectly through changes in soil quality, pests, and diseases. In particular, the agricultural production is expected to decline in tropical and sub-tropical countries (developing world), whereas some parts of world, especially the places in northern latitude above about 55 may be benefited from the climate change (Parry et al., 2004; Stern, 2006; Hadley-Centre, 2006) ${ }^{[5]}$. The continued impact of elevated $\mathrm{CO} 2$, rising temperature and varying rainfall on crop behaviour is very complex. It is important to understand this phenomenon of climate change on crop production and to develop adaptation strategies for sustainability in food production, using a suitable validated crop simulation models. The simulation output can adequately describe relative trends in yields caused by environment variation (Penning de Vries et al., 1989) ${ }^{[17]}$.

Many crop simulations models have been evaluated and used to assist the decision making process in agriculture (Muchow and Belamy, 1991; MacRobert and Savage, 1998) [14, 13]. Decision Support System for Agro technology Transfer (DSSAT), which is a combination of several dynamic crop simulation models, can predict accurately the growth, development and yield of crops with the help of soil, daily weather and management inputs, to aid farmers in developing long-term strategies (Tsuji et al., 1994). The DSSAT has unique feature of using historical or future weather data to predict the yields under different management options. CERES (Crop Environment Resource Synthesis) Rice model available in DSSAT simulate crop growth, development and yield taking into account the effects of weather, genetics, and soil and management parameters. The model can be used to evaluate uncertainties and risk associated with rice production system. The present rice production in India concerns with the climatic risk due to global warming. Because of this, an estimation of likely impact is vital in planning strategies to meet the increased rice demand of ever growing population pressures.

The objectives of the present investigation were (1) to simulate the impact of climate change on rice yields and (2) to evaluate varietal adaptation to climate change scenarios.

\section{Materials and methods}

The study was carried out in the Department of Agrometeorology, Sam Higginbottom University of Agriculture, Technology and Sciences, Naini, Prayagraj. Prayagraj is taken as the representative experimental site for this study. It is situated at an elevation of $94 \mathrm{~m} \mathrm{(295} \mathrm{ft.)} \mathrm{above}$ mean sea level at $25^{\circ} 43^{\prime} \mathrm{N}$ latitude and $81^{\circ} 84^{\prime}$ E longitude. Prayagraj has a humid sub-tropical climate.

\subsection{Weather data}

Allahabad (Prayagraj) has a humid subtropical climate common to cities in the plains of North India, designated Cwa in the Köppen climate classification. The climate of Allahabad district is characterized by a long and hot summer, a fairly pleasant monsoon and cold seasons. The winter usually extends from mid-November to February and is followed by the summer which continues till about the middle of June.

The weather data (daily basis) on maximum and minimum temperatures, rainfall and solar radiation of ten years (2012 2019) for centre Prayagraj was obtained from Department of Environmental science and NRM, College of Forestry, Sam Higginbottom University of Agriculture, Technology and Sciences. The complete weather data sets without any discrepancies are needed for crop simulation models to calculate dry matter accumulation and to determine the physiological development of the crop. Solar radiation was calculated by the model based on Hargreaves method, which is reported to be best suited for Indian conditions.

From about the middle of November, the temperatures begin to fall rapidly and in January (the coldest month) the mean daily maximum is $23.7^{\circ} \mathrm{C}\left(74.7^{\circ} \mathrm{F}\right)$. May usually being the hottest month of the year with the mean daily maximum temperature at $41.8^{\circ} \mathrm{C}\left(107.2^{\circ} \mathrm{F}\right)$ and the mean daily minimum at $26.8^{\circ} \mathrm{C}\left(80.2^{\circ} \mathrm{F}\right)$. The city receives 2916 hours of sunshine per year, maximum sunlight in May. The climate is marked by high relative humidity i.e. 70 to 80 percent during monsoon and progressive decrease in humidity (during the summers humidity is very low i.e. 15 to 20 percent only).

\subsection{Soil data}

Layer wise $(0-120 \mathrm{~cm})$ data of soil physical and chemical properties which includes Bulk density, Hydraulic conductivity, as organic carbon, clay contents, silt contents, soil pH organic carbon content, clay and silt content etc. of Prayagraj district was collected from India Meteorological Department, New Delhi.

\subsection{Cultivar data}

These coefficients are crucial because they strongly influence the simulation of growth and development of the crop. The CERES-Rice model uses eight genetic coefficients viz., P1, P2O, P2R, P5, G1, G2, G3 and G4. The eight coefficients for three cultivars (NDR - 359 and NDR - 97) are collected from IMD, New Delhi then again they are calibrated for Prayagraj condition via trial and error method. The genetic coefficients for the two varieties are shown in table 2 below in result and discussion and description of genetic coefficients are as follows:

Table 1: Description of genetic coefficient

\begin{tabular}{|c|c|}
\hline GC & Description \\
\hline P1 & Juvenile phase coefficient \\
\hline P2O & Critical photoperiod \\
\hline P2R & Photoperodism coefficient \\
\hline P5 & Grain filling duration coefficient \\
\hline G1 & Spikelet number coefficient \\
\hline G2 & Single grain weight \\
\hline G3 & Tillering coefficient \\
\hline G4 & Temperature tolerance coefficient \\
\hline
\end{tabular}

\subsection{Crop management and experimental data}

The eight years $(2012$ - 2019) experimental data conducted at the College of Forestry farm, Sam Higginbottom University of Agriculture, Technology and Sciences, Prayagraj, UP, India was used for the calibration and validation of model.

This experiment was carried out to assess the yield of two cultivar of rice var. NDR - 359 and NDR - 97 for eight years under Prayagraj condition. Experiment includes 2 cultivars which the experiments were conducted based on split plot design. Planting dates were $1^{\text {st }}$ week of July for every cultivar. Grain yield was provided for the model as observed data for the calibration and validation of model.

\subsection{CERES - Rice model}

The windows-based CERES-Rice model (DSSAT version 4.0) released during the year 2004 by International Consortium for Agricultural Systems Application; University of Hawaii, USA was used for this study. The various processes simulated by this model are phenological 
development of the crop; growth of leaves, stems and roots; biomass accumulation and partitioning among leaves, stem, panicle, grains and roots; soil water balance and water use by the crop; and soil nitrogen transformations and uptake by the crop. The phenological stages simulated by the model are sowing or transplanting, germination, emergence, juvenile phase, panicle initiation, heading, beginning of grain filling, end of grain filling, and physiological maturity. The model simulates total biomass of the crop is the product of the growth duration and the average growth rate. The simulation of yields at the process level involves the prediction of these two important processes. The economic yield of the crop is the fraction of total biomass partitioned to grain.

Crop growth is simulated by employing a carbon balance approach in a source-sink system (Ritchie et al., 1998).

Detailed description of the model can be found in Hunt and Boote (1998) ${ }^{[6]}$. The model is based on understanding of plants, soil, weather and management interaction to predict growth and yield. Yield limiting factors like water and nutrient stresses (Nitrogen and phosphorus) are considered by the model. The pest problems, weeds, and diseases, as the yield reducing factors are also covered by the model.

\subsection{Model calibration}

The CERES-Rice model was calibrated first to fit the model in the specific soil and environmental conditions. Genetic coefficients for the rice cultivars NDR - 359 and NDR - 97 were calibrated using experimental data of eight years on grain yield at optimum irrigated condition.

\subsection{Model validation}

Validation is the comparison of the results of model simulations with observations from crops that were not used for the calibration. A model should be rigorously validated under widely differing environmental conditions to evaluate the performance of major processes in addition to its ability to predict the phenology and yield. Before any model can be used with confidence, adequate validation or assessment of the magnitude of the errors that may result from its use should be performed. Model validation, in its simplest form is a comparison between simulated and observed values.

Several criteria were used to quantify the differences between observed and simulated data. Test criteria have been separated into two groups, called summary measures and difference measures. The summary measures describe the quality of simulation while the difference measures try to locate and quantify errors. The latter include the root mean square error (RMSE) and the normalised root mean square error (NRMSE). NRMSE gives a measure (\%) of the relative difference of simulated verses observed data. The simulation is considered excellent with a normalized RMSE less than $10 \%$, good if the normalized RMSE is greater than 10 and less than 20\%, fair if the normalized RMSE is greater than $20 \%$ and less than $30 \%$, and poor if the normalized RMSE is greater than 30\% (Loague and Green, 1991).

They were calculated according to Willmott as follows and were based on the terms $\left(\mathrm{Sim}_{\mathrm{i}}-\mathrm{Obs}_{\mathrm{i}}\right)$.

RMSE $=\sqrt{\frac{\sum_{i=1}^{n}\left(X_{\mathrm{obs}_{i}}-X_{\mathrm{sim}_{\mathrm{i}}}\right)^{2}}{n}}$
$\mathrm{nRMSE}=\sqrt{\sum_{i=1}^{n} \frac{(S i-O b)^{2}}{n}} \times \frac{100}{M}$

Varshneya (1999), who gave a simple indication of error in prediction, defined the Percent Error (PE). PE is defined as ratio of RMSE to mean observed value expressed as percentage. Percent Error seems to be accurate when its value is below $15 \%$ and was calculated as follows:

Error Percent $=\sqrt{\frac{\left(X_{\text {sim }_{t}}-X_{\text {oḅ̣ }}\right)}{X_{\text {sim }}}} \times 100$

Note: (i) In RMSE and PE equations, $X_{o b s}$ is observed values and $\mathrm{X}_{\text {sim }}$ is modelled (simulated) values at time/place $i$.

(ii) In NRMSE equation, $S_{i}$ is simulated value and $O_{b}$ is observed value.

\section{Result and discussion}

\subsection{Grain yield}

Simulated grain yield with observed yield is listed in table 1 for cultivar NDR - 359 and NDR - 97 respectively. The average simulated yield of NDR - 359 is $6258.375 \mathrm{~kg}$ and NDR - 97 is $4520.25 \mathrm{~kg} \mathrm{ha}^{-1}$. The range of magnitude of deviation between simulated and grain yield varied between $89 \mathrm{~kg} \mathrm{ha}^{-1}$ to $569 \mathrm{~kg} \mathrm{ha}^{-1}$. The values of errors as computed in terms of RMSE is 335.31 and 643.76 for NDR-359 and NDR - 97 respectively, NRMSE is 0.05 and 0.08 for NDR 359 and NDR - 97 respectively with an average percent error of 2.36 and 4.84 for NDR - 359 and NDR - 97 respectively which indicated that model performed well in all the years in predicting the grain yield of rice for every cultivar.

For medium duration variety (NDR - 359) the variation between mean simulated and mean observed grain yield was $2.73 \%$ and $4.82 \%$ for the variety NDR -97 . The simulated grain yield of NDR - 359 was closer to observed value.

Table 2: Simulated and Observed yield.

\begin{tabular}{|c|c|c|c|}
\hline \multicolumn{2}{|c|}{ NDR - 359 } & \multicolumn{2}{c|}{ NDR - 97 } \\
\hline Obs. Yield (Kg/ha) & Sim. Yield (Kg/ha) & $\begin{array}{c}\text { Obs. Yield } \\
\text { (Kg/ha) }\end{array}$ & $\begin{array}{c}\text { Sim. yield } \\
\text { (Kg/ha) }\end{array}$ \\
\hline 6037 & 5846 & 4213 & 4526 \\
\hline 5986 & 6555 & 4192 & 4658 \\
\hline 6071 & 6395 & 4232 & 3911 \\
\hline 6170 & 6509 & 4290 & 4662 \\
\hline 6079 & 6473 & 4397 & 4713 \\
\hline 6138 & 5986 & 4345 & 4753 \\
\hline 6199 & 6032 & 4356 & 4445 \\
\hline 6019 & 6271 & 4387 & 4494 \\
\hline 6087.37 & 6258.37 & 4302 & 4520.25 \\
\hline
\end{tabular}

Table 3: Calibrated genetic coefficient for 2 different cultivars of rice at Prayagraj condition.

\begin{tabular}{|c|c|c|c|c|c|c|c|c|}
\hline Cultivar & P1 & P2R & P5 & P2O & G1 & G2 & G3 & G4 \\
\hline NDR 359 & 500.0 & 200.0 & 450.0 & 12.5 & 62.0 & 0.190 & 1.00 & 1.00 \\
\hline NDR 97 & 300.0 & 120.0 & 390.0 & 11.5 & 59.0 & 0.220 & 1.00 & 1.00 \\
\hline
\end{tabular}

\subsection{Yield simulation for climate change scenario}

The model was used to simulate grain yield of varieties at their optimum $\mathrm{N}$ application rate using historical weather data and developed climate change scenarios. 


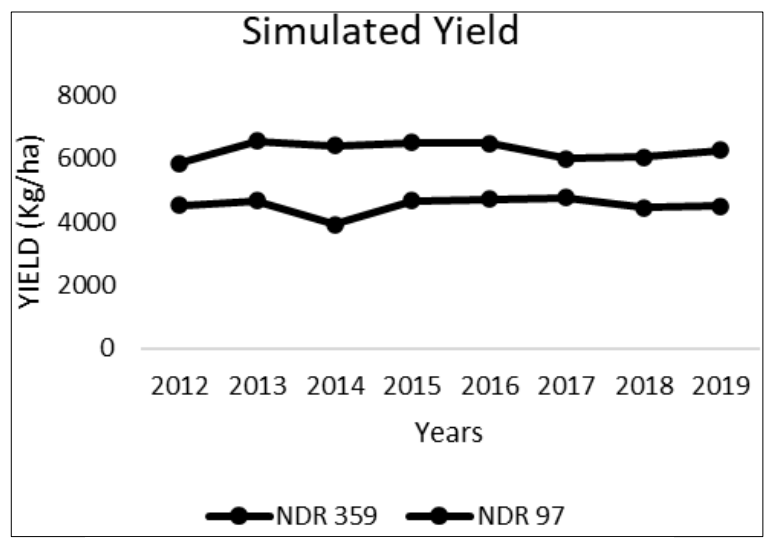

Fig 1: Simulated grain yield of NDR 359 and NDR - 97 over year 2012 - 2019

a) Historical weather data: The model was applied to simulate grain yield of both varieties at Prayagraj region for irrigated condition using historical weather data of past 8 years (Figures 1 and 2). The grain yield of NDR 359 ranged from 5846 to $6555 \mathrm{~kg} / \mathrm{ha}$ with a mean yield $6258.375 \mathrm{~kg} / \mathrm{ha}$. The variation in grain yield of NDR - 97 was in the range $3911 \sim 4753 \mathrm{~kg} / \mathrm{ha}$ and the mean yield was $4520.25 \mathrm{~kg} / \mathrm{ha}$. The variations in grain yield across the past years were low for the medium duration varieties and high for the early duration variety. However, the mean simulated grain yield of the medium duration variety was higher than early duration varieties (Figure 2).
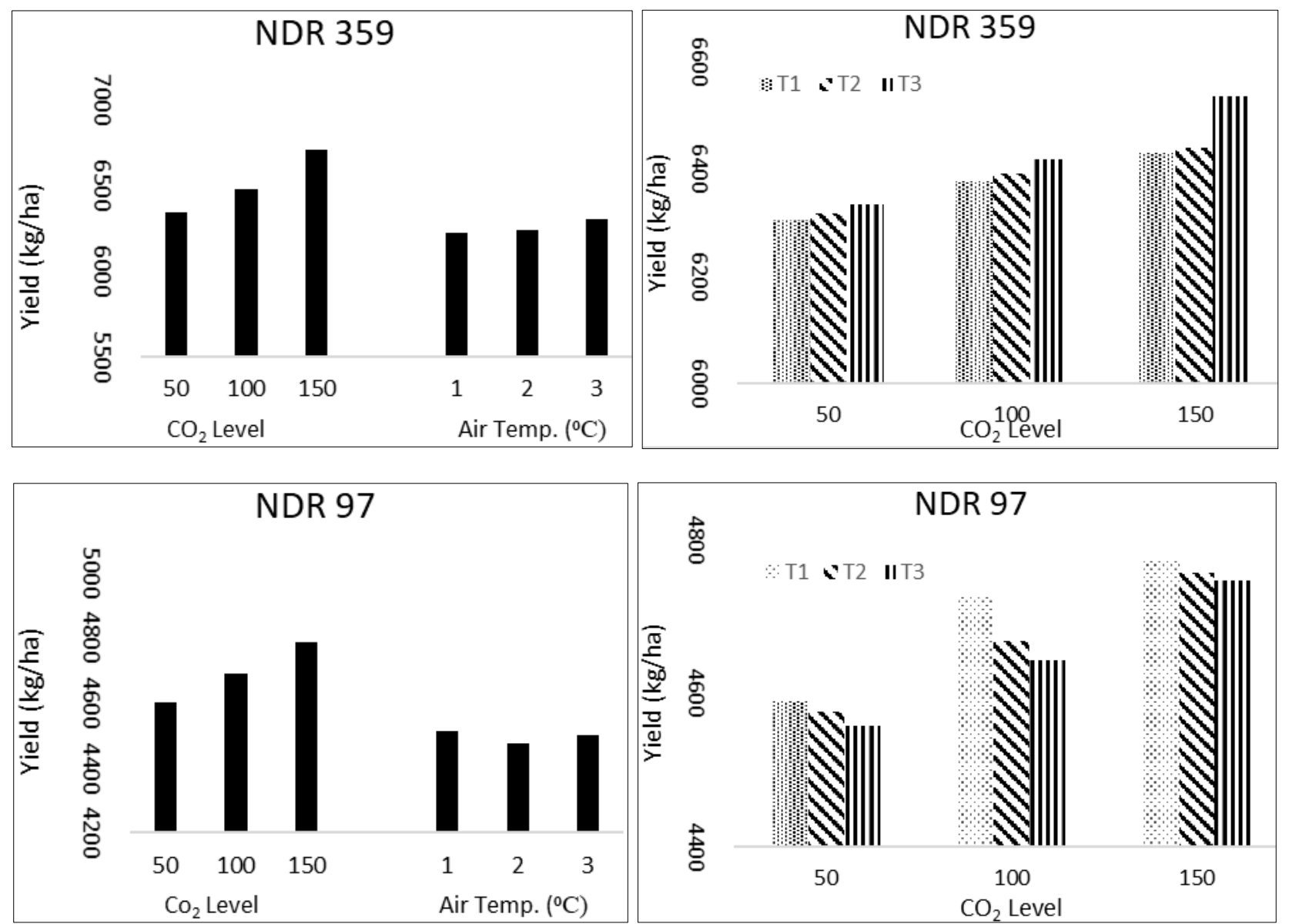

Fig 3: Effect of increasing $\mathrm{CO}_{2}$ level of 50,100 and $150 \mathrm{ppm}$ and rise in air temperature by $1^{\circ} \mathrm{C}(\mathrm{T} 1), 2^{\circ} \mathrm{C}(\mathrm{T} 2)$, and $3^{\circ} \mathrm{C}(\mathrm{T} 3)$ above ambient in the atmosphere on grain yield of rice varieties NDR - 359 and NDR - 97 simulated in Prayagraj region. b) Developed climate change scenario: The grain yield of all varieties was simulated at their optimum $\mathrm{N}$ application without any water stress for rising $\mathrm{CO} 2$ level and temperature scenarios. Increase in $\mathrm{CO} 2$ level increased the grain yield of all the varieties (Figure 6). With increase in $\mathrm{CO} 2$ level by 50 to $100 \mathrm{ppm}$, the yield increased by 1.5 to $3.0 \%$ for medium duration varieties IR 36 and Lalat and 3 to $6 \%$ for the long duration variety Swarna. Increasing $\mathrm{CO} 2$ level increases the photosynthetic activity of the crop and thereby the yield. 
Summarizing the data from several experimental studies on different agricultural crops, Kimbal et al. (2002) ${ }^{[10]}$ found a $30 \%$ increase in growth rate with a doubling of $\mathrm{CO}_{2}$ levels. Nevertheless, the experimental findings from the growth chamber studies (Baker et al., 1992) [2] showed a $32 \%$ increase in rice grain yield due to doubling of the $\mathrm{CO}_{2}$ concentration from 330 to $660 \mu \mathrm{mol} \mathrm{CO} \mathrm{mol}^{-1}$ air (ppm). The increased growth response with increasing $\mathrm{CO}_{2}$ concentration was attributed to greater tillering and more grain-bearing panicles. In our study the model also simulated a comparative yield increase about $7 \%$ with $150 \mathrm{ppm}$ increase in $\mathrm{CO}_{2}$ level.

Increase in temperature up to $3{ }^{\circ} \mathrm{C}$, resulted a marginal increase $(<1 \%)$ in grain yield of medium duration variety and the yield of the early duration variety was decreases marginally $(<1 \%)$ with similar increase in temperature. Many researchers have stated increase in yield with elevated $\mathrm{CO}_{2}$ level and decrease in yield with rise in temperature (Krishnan et al., 2007; Saseendran et al., 2000; Singh and Ritchie, 1993; Singh and Padilla, 1995) ${ }^{[11]}$. In our simulation study, the medium duration variety NDR - 359 performed better than early duration variety with $3^{\circ} \mathrm{C}$ rise in temperature and 150 ppm increase in $\mathrm{CO}_{2}$ level over ambient value. The variety NDR - 359 adapted better to rising temperature as compared to other varieties.

\section{Conclusion}

CERES-Rice model was able to simulate grain yield with good accuracy under varying management levels. The model provides insights about the response mechanism to irrigated condition management and various weather conditions. The simulated grain yield of the medium duration variety NDR 359 was found to be more stable with a higher mean yield as compared to early duration variety in irrigated condition. However the variety NDR - 359 showed better adaptability to climate change scenarios under optimum input management condition.

\section{Reference}

1. Aggarwal PK. Impact of climate change on Indian agriculture, J. Plant Biol. 2003; 30:189-198.

2. Baker JT, Allen Jr, LH, Boote KJ. Effects of CO2 and temperature on growth and yield of rice, J. Exp. Bot. 1992; 43:959- 964.

3. Baker JT, Allen LH Jr, Boote KJ, Pickering NB. Direct effects of atmospheric carbon dioxide concentration on whole canopy dark respiration of rice, Global Change Biol. 2000; 6:275-286. doi:10.1046/j.1365-2486.2000.00306.x.

4. Gomez KA, Gomez AA. Statistical Procedures for Agricultural Research, 2nd ed. John Wiley and Sons, New York, NY, 1984, 680p.

5. Hadley-Centre. Effects of climate change in the developing countries, UK Meteorological Office, 2006.

6. Hunt LA, Boote KJ. Data for model operation, calibration, and evaluation, in G. Y. Tsuji et al. (Eds.), Understanding Options for Agricultural Production. Kluwer Academic Publishers in cooperation with International Consortium for Agricultural Systems Applications, The Netherlands, 1998, 9-40.

7. Jackson ML. Soil chemical analysis (First Ed.), Prentice Hall of India Pvt. Ltd., New Delhi, 1967.

8. Jackson ML. Soil chemical analysis (Second Ed.), Prentice Hall of India Pvt. Ltd., New Delhi, 1973.
9. Kim HY, Lieffering M, Kobayashi K, Okada M, Miura S. Seasonal changes in the effects of elevated $\mathrm{CO} 2$ on rice at three levels of nitrogen supply: A free air $\mathrm{CO} 2$ enrichment (FACE) experiment, Global Change Biol. 2003; 9:826-837. doi:10.1016/j.fcr.20 06.07.003.

10. Kimbal BA, Kobayashi K, Bindi M. Responses of agricultural crops to free air $\mathrm{CO} 2$ enrichment, Adv. Agron. 2002; 77:293-368.

11. Krishnan P, Swain DK, Chandra BB, Nayak SK, Dash $\mathrm{RN}$. Impact of elevated $\mathrm{CO} 2$ and temperature on rice yield and methods of adapataions as evaluated by crop simulation studies, Agriculture Ecosystem \& Environment. 2007; 122:233-242.

12. Ladha JK, Pathak H, Tirol-Padre A, Dawe D, Gupta R. Productivity trends in intensive rice-wheat cropping systems in Asia, in: Ladha et al. (Eds.), Improving the productivity and Sustainability of Rice-Wheat Systems: Issues and Impacts. ASA Special Publication Number. 2003; 65:45-76.

13. MacRobert JF, Savage MJ. The use of a crop simulation model for planning wheat irrigation in Zimbabwe, in G.Y. Tsuji, G. Hoogenboom and P.K. Thornton (eds.), Understanding options for agricultural production, 1998.

14. Muchow RC, Bellamy JA. Climatic risk in crop production: Models and management for the Semiarid Tropics and Subtropics, C.A.B. International, Wallingford, Oxon, UK, 1991.

15. Pathak H, Ladha JK, Aggarwal PK, Peng S, Das S, Yadvinder- Singh et al. Trends of climatic potential and on-farm yields of rice and wheat in the Indo-Gangetic plains, Field Crops Res. 2003; 80:223-234.

16. Patil SK, Singh U, Singh VP. Nitrogen dynamics and crop growth on alfsol and vertisol under direct seeded rainfed lowland rice based system, Field Crop Res. 2001; 70:185-199.

17. Penning de Vries FWT, Jansen DM, ten Berge HFM, Bakema A. Simulation of Eco physiological processes of Growth in Several Annual Crops. PUDOC, Wageningen, the Netherlands, 1989, 271p.

18. Swain DK, Yadav A. Simulating the Impact of Climate Change on Rice Yield Using CERES-Rice Model, Journal of Environmental Informatics. 2009; 13(2):104110 . 